Gömülü 3. molar

dişlerin cerrahi

çekimleri sonrası

gönüllülerin kendi

değerlendirdikleri VAS

ödem skorlamalarının,

hekim tarafından yüzde

yapılan ödem ölçümleri ile

korelasyonunun

değerlendirilmesi

\section{Evaluation of \\ correlation between \\ patients subjective VAS \\ edema scores and \\ surgeons measurement \\ scores on face after \\ surgical removal of \\ Impacted mandibular third molars}

\section{Arş. Gör. İbrahim Murat Afat}

Marmara Üniversitesi, Diş Hekimliği Fakültesi, Ağız, Diş ve Cene Cerrahisi A. D, İstanbul

\section{Arş. Gör. Emine Tuna Akdoğan}

Marmara Üniversitesi, Diş Hekimliği Fakültesi, Ağız, Diş ve Çene Cerrahisi A.D, İstanbul

Doç. Dr. Onur Gönül

Marmara Üniversitesi, Diş Hekimliği Fakültesi, Ağız, Diş ve Çene Cerrahisi A.D, İstanbul

Prof. Dr. Mehmet Kamil Göker

Marmara Üniversitesi, Diş Hekimliği Fakültesi, Ağız, Diş ve çene Cerrahisi A.D, İstanbul

Geliș Tarihi: 7 Haziran 2017

Kabul Tarihi: 14 Haziran 2017

doi: 10.5505/yeditepe.2017.72792

\section{Yazışma Adresi:}

Arş. Gör. İbrahim Murat Afat

Başıbüyük Mahallesi, Başıbüyük Yolu 9/3, 34854

Başıbüyük/ Maltepe/ İstanbul

Tel: 00902164211621

E-posta: muratafat2@gmail.com
ÖZET

Amaç: Bu çalışmanın amacı gömülü 3. molar dişlerin cerrahi çekimi sonrası yüzde oluşan ödemi ölçmek amacıyla en sık kullanılan yöntem olan katlanabilir cetvelle hekim tarafından yüzde yapılan iki sabit nokta arası mesafe ölçümleri ile hastanın ayna karsısında VAS ödem skalası yardımıyla kendisinin yaptığı sübjektif skorlama arasındaki korelasyonu değerlendirmektir.

Gereç ve Yöntem: Kliniğimize gömülü alt yirmi yaş dişlerinin çekilmesi talebiyle başvuran hastalar arasından çalışmaya dahil edilme kriterlerine uygun olan 60 hasta dahil edildi. Yüzde oluşacak ödemin takibi amacıyla Tragus-Pogonion arası, Tragus-Labial Commissure arası, Angulus Mandibula-Lateral Canthus arası mesafeler preoperatif, postoperatif 2.gün ve 7.gün ölçülüp kaydedildi. Bu ölçümlere ek olarak hastalar verilen form üzerindeki açıklamalı VAS ödem skalası yardımıyla postoperatif şişlik ve fonksiyon kaybı değerlendiridi.

Bulgular: 2.gün VAS ödem skoru ile preoperatif ölçüme göre 2.gün tragus-pogonion arası mesafesinde görülen artış miktarı arasında pozitif yönlü, \% 28.2 düzeyinde ve istatistiksel olarak anlamlı bir ilişki bulunmaktadır ( $p: 0.029 ; p<0.05$ ). 7.gün VAS ödem skoru ile 7.gün Tragus-Labial Commissure arası mesafesinde görülen artış miktarı arasında pozitif yönlü, \% 28.7 düzeyinde ve istatistiksel olarak anlamlı bir ilişki bulunmaktadır ( $p: 0.026 ; p<0.05)$. 2.gün VAS ödem skoru ile preoperatif ölçüme göre 2.gün ağız açıklı̆ında görülen düşüş miktarı arasında pozitif yönlü, \% 30.8 düzeyinde ve istatistiksel olarak anlamlı bir ilişki bulunmaktadır ( $\mathrm{p}: 0.017 ; \mathrm{p}<0.05)$. Diğer ölçümler ile ilgili günlerin VAS Ödem skalası skorları arasında istatistiksel olarak anlamlı bir ilişki bulunmamaktadır.

Sonuç: Literatürde tarif edilen diğer ödem değerlendirme tekniklerine ek olarak kullanıldığı taktirde; VAS ödem skalasının postoperatif dönemde ödem ve trismus miktarını değerlendirmek amacıyla herhangi bir ek maliyet yaratmadan elde edilen verilere katkı sağlayacağını düşünmekteyiz.

Anahtar kelimeler: Gömülü diş, ödem, VAS

\section{SUMMARY}

Aim: The aim of this study is to evaluate the correlation between two point distance measurements achieved by surgeon on patients face with foldable ruler, which is the most commonly used method, and the subjective scoring done by the patient with the help of the VAS edema scale.

Materials and Methods: Sixty patients were included in the study, who were admitted to our clinic with the request of extraction of wisdom teeth. In order to evaluate postoperative edema, the distances between Tragus-Pogonion, Tragus-Labial Commissure, Angulus Mandibula-Lateral Canthus were measured preoperatively, postoperative $2^{\text {nd }}$ day and $7^{\text {th }}$ day. In addition to these measurements, patients assessed postoperative swelling and loss of function themselves with the 
help of the VAS edema scale.

Results: There was a statistically significant correlation (28.2\%) between the $2^{\text {nd }}$ day VAS edema score and the edema level seen in $2^{\text {nd }}$ day in Tragus-Pogonion measurements ( $p: 0.029 ; p<0.05)$. There was a statistically significant correlation (28.7\%) between the $7^{\text {nd }}$ day VAS edema score and the edema seen in $7^{\text {nd }}$ day in Tragus-Labial Commissure measurements ( $p: 0.026 ; p<0.05)$. There was a statistically significant correlation (\%30.8) between the $2^{\text {nd }}$ day VAS edema score and the trismus level seen in $2^{\text {nd }}$ day ( $\left.p: 0.017 ; p<0.05\right)$. No statistically significant relationship was observed between the VAS edema scale scores and surgeon's measurement scores at the other assessment times.

Conclusions: As a conclusion, if used as an addition to other edema assessment techniques described in the literature, VAS edema scales will contribute to the data obtained, without any additional cost, in order to evaluate the amount of edema and trismus seen in postoperative period.

\section{Keywords: Edema, impacted tooth, VAS}

\section{GíRiş}

Yirmi yaş dişi cerrahisi sonrası ödem oluşması beklenen bir klinik tablodur. Cerrahi travmaya bağlı oluşan doku yanıtının sebebi tüm hastalarda aynı olsa da şiddeti farklılık gösterebilir. İlgili bölgede hasar gören doku miktarına bağlı olarak oluşan ödem miktarı cerrahi girişimden sonraki 24 - 48 saat içerisinde maksimuma ulaşır ve postoperatif üçüncü ve dördüncü günde azalmaya başlar. Klinik olarak ödem düz, soluk ve gergin cilt ile karakterizedir ve gömülü yirmi yaş dişi cerrahisinden sonra hastaların yaşam konforunu azaltan faktörlerin en önemlilerindendir.

Ameliyat sonrası yüzde oluşan ödemin ölçülmesine yönelik son 60 yılda çeşitli yöntemler kullanıldığı görülmektedir. Yirmi yaş dişi cerrahisinden sonra oluşan ödem ilk zamanlar çoğunlukla subjektif olarak değerlendirilmiştir. Zaman içerisinde yüz morfolojisindeki değişiklikleri tanımlamak ve ölçümler yapmak için matematiksel yöntemlerin kullanıldığı görülmektedir. ${ }^{2}$

Günümüzde sıklıkla yüzde belirlenen referans noktaları arasındaki mesafelerin metrik olarak ölçülmesi ile ödem değerlendirilmektedir. Bu amaçla en sık kullanılan dört referans noktasl; tragus, lateral kantus, gonion ve yumuşak doku pogoniondur. ${ }^{3,4}$ Hastaların kendilerinin yaptığı subjektif değerlendirmeleri içeren VAS (Görsel Analog Skala) ödem skalaları da çalışmalarda sıklıkla kullanılmaktadır. 5,6

Bu tekniklerin yanı sıra yüzdeki șişliği değerlendirmek amacıyla; lateral ve anteroposterior grafilerin, profil fotoğraflarının, stereofotografinin, bilgisayarlı tomografilerin, MRI ve ultrasonografilerin kullanıldığı teknikler de literatürde tarif edilmektedir. ${ }^{7-10}$
Bu çalışmada en sık kullanılan yöntem olan katlanabilir cetvelle hekim tarafından yüzde yapılan iki sabit nokta arası mesafe ölçümleri ile hastanın ayna karsısında VAS Ödem skalası yardımıyla yaptığı subjektif skorlama arasındaki ilişkinin değerlendirmesi amaçlandı.

\section{GEREÇ VE YÖNTEM}

Çalışmaya, ilgili kurumdan etik kurul onayı alındıktan sonra (T.C. Marmara Üniversitesi Diş Hekimliği Fakültesi Klinik Araştırmalar Etik Kurulu Protokol Kodu: 2016-50) Marmara Üniversitesi Diş Hekimliği Fakültesi Ağız Diş ve Çene Cerrahisi Anabilim Dalı Kliniği'ne gömülü alt yirmi yaş dişlerinin çekilmesi talebiyle başvuran hastalar arasından çalışmaya dahil edilme kriterlerine uygun olan, çekim endikasyonu konulmuş, enfeksiyon belirtisi bulunmayan, Pell ve Gregory Sınıflaması'na göre Sınıf 1 Pozisyon B ve komsu 2. molar dişe göre açısı 25- 40 dereceye kadar mezioanguler konumda yarı gömülü mandibular 3. molar dişi bulunan 60 gönüllü dahil edildi. Bütün gömülü diş çekimleri aynı araştırmacı tarafından bütün gruplarda aynı teknik ile asepsi ve antisepsi kurallarına uyularak gerçekleştirildi.

Yüzde oluşacak ödemin değerlendirilmesi amacıyla katlanabilir plastik cetvel yardımıyla hastanın yüzünde 3 mesafe ölçümü gerçekleştirildi. Bu ölçümler;

\section{- Tragus-Pogonion arası,}

- Tragus-Labial Commissure arası,

\section{- $\quad$ Angulus Mandibula-Lateral Canthus arası}

olacak şekilde preoperatif, postoperatif 2. gün ve 7. günlerde ölçülüp mm cinsinden tablo üzerine kaydedildi.

Ağız açıklığındaki kısıtlanma (trismus) değerlendirilmesi amacıyla hastanın yardımsız maksimum ağız açıklığı esnasında sağ 1. üst keserin mezioinsizal kenarı ile sağ 1. alt keserin mezioinsizal kenarı arasındaki mesafe preoperatif, postoperatif 2. gün ve 7. gün zamanlarında cetvel ile ölçülüp mm cinsinden tablo üzerine kaydedildi.

Bu ölçümlere ek olarak hastaya verilen form üzerinde bulunan, Berge tarafından tanımlanan şekilde, açıklamalı ödem VAS skalası yardımıyla da postoperatif şişlik ve fonksiyon kaybı değerlendiridi. Hasta ayna karşınında iken postoperatif 6 . saat, 24. saat, 2. gün, 3. gün, 4. gün, 5. gün, 6. gün ve 7. gün zamanlarında form üzerinde, "0 = Hiç şişlik yok" - " $5=$ Aşıı şişlik var ve ağzımı açmakta zorlanıyorum" olacak şekilde, 0 ile 5 arasında bir değer olarak hasta tarafından form üzerindeki tabloya işaretlendi. ${ }^{5}$ (Tablo 1 )

Çalışmada elde edilen bulgular değerlendirilirken, istatistiksel analizler için IBM SPSS Statistics 22 (IBM SPSS, Türkiye) programı kullanıldı. Çalışma verileri değerlendirilirken parametrelerin normal dağılıma uygunluğu Shapiro Wilks testi ile değerlendirilmiştir. Çalışma verileri değerlendirilirken normal dağılım gösteren parametrelerin gruplar arası karşılaştırmalarında Oneway Anova 
testi kullanıldı. Normal dağılıma uygunluk göstermeyen parametreler arasındaki ilișkilerin incelenmesinde Spearman's rho korelasyon analizi kullanıldı. Çalışmanın genel anlamlıık $p<0.05$ düzeyinde değerlendirildi. Bonferroni düzeltmelerinde p:0.05, ikili karşılaştırma sayılarına bölünmek suretiyle yeni anlamlılı düzeyleri belirlendi.

Tablo 1. Ödem skalası değerlerin anlamı.

\begin{tabular}{|l|l}
\hline 0 - Hiç şişlik yok & Yüzümde şişlik fark etmiyorum. \\
\hline 1- Hafí şşşlik var & Hafif bir şişlik var ama fark edilir değil. \\
\hline 2- Orta dereceli & Şişlik fark edilir durumda ama çiğneme yutma hareketlerine engel olmuyor. \\
\hline 3- Ciddi şş̧lik var & Şişlik fark edilir durumda ve çiğneme hareketlerime engel yaratıyor. \\
\hline 4- Çok Ciddi şişlik & Şişlik belirgin ve çiğneme hareketlerime engel yaratıyor ama ağzımı \\
var & açabiliyorum. \\
\hline 5- Aşırı şişlik var & Ciddi fark edilir şişlik var ve ağżmı açmakta zorlanıyorum. \\
\hline
\end{tabular}

\section{BULGULAR}

2.gün VAS ödem skoru ile preoperatif ölçüme göre 2. gün tragus-pogonion arası mesafesinde görülen artış miktarı arasında pozitif yönlü, \%28.2 düzeyinde ve istatistiksel olarak anlamlı bir ilişki bulunmaktadır ( $p: 0.029 ; p<0.05$ ). 7.gün VAS ödem skoru ile preoperatif ölçüme göre 7. gün tragus-pogonion arası mesafesinde görülen artış miktarı arasında istatistiksel olarak anlamlı bir ilişki bulunmamaktadır ( $p>0.05$ ). (Tablo 2, Grafik 1)

Tablo 2. VAS ödem 2.gün ve 7.gün skorları ile aynı günlerdeki mesafe ölçümlerinde görülen değişim miktarları arasındaki korelasyon.

\begin{tabular}{|c|c|c|c|c|}
\hline & & & \multicolumn{2}{|c|}{ VAS Ödem } \\
\hline & & & 2.gün & 7.gün \\
\hline \multirow{4}{*}{$\begin{array}{l}\text { Tragus-Pogonion } \\
\text { arası }\end{array}$} & 2.gün & $\mathrm{r}$ & 0,282 & \\
\hline & & $\mathrm{p}$ & $0,029 *$ & \\
\hline & 7.gün & $r$ & & 0,147 \\
\hline & & $\mathrm{p}$ & & 0,262 \\
\hline \multirow{4}{*}{$\begin{array}{l}\text { Tragus-Labial } \\
\text { Commissure arası }\end{array}$} & 2.gün & $r$ & 0,143 & \\
\hline & & $\mathrm{p}$ & 0,275 & \\
\hline & 7.gün & $r$ & & 0,287 \\
\hline & & $\mathrm{p}$ & & $0,026^{*}$ \\
\hline \multirow{2}{*}{ Angulus Mandibula- } & 2.gün & $\mathrm{r}$ & $-0,031$ & \\
\hline & & p & 0,815 & \\
\hline Lateral Canthus & 7.gün & $\mathrm{r}$ & & 0,176 \\
\hline arası & & $\mathrm{p}$ & & 0,179 \\
\hline
\end{tabular}

Spearman's rho korelasyon Analizi

$* p<0.05$

istatistiksel olarak anlamlı bir ilişki bulunmamaktadır ( $p>0.05$ ). 7.gün VAS ödem skoru ile 7. gün tragus-labial commissure arası mesafesinde görülen artış miktarı arasında pozitif yönlü, \%28.7 düzeyinde ve istatistiksel olarak anlamlı bir ilişki bulunmaktadır (p:0.026; $p<0.05)$
(Grafik 2).

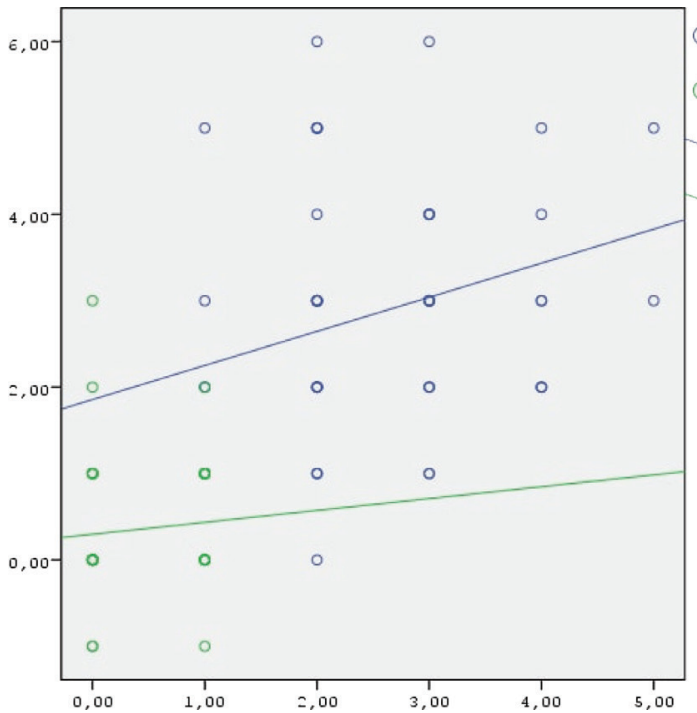

Tragus-pogonion

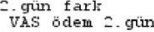
Tragus-Pogonion
7 . crin farjs

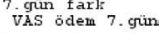
Traçus-Pogonion VAS odem 2 - gin Tragus-Pogonion
7. $\operatorname{cin}$ farls

Resim 1. VAS ödem 2.gün ve 7.gün skorları ile aynı günlerdeki mesafe ölçüm lerinde görülen değişim miktarları arasındaki korelasyon.

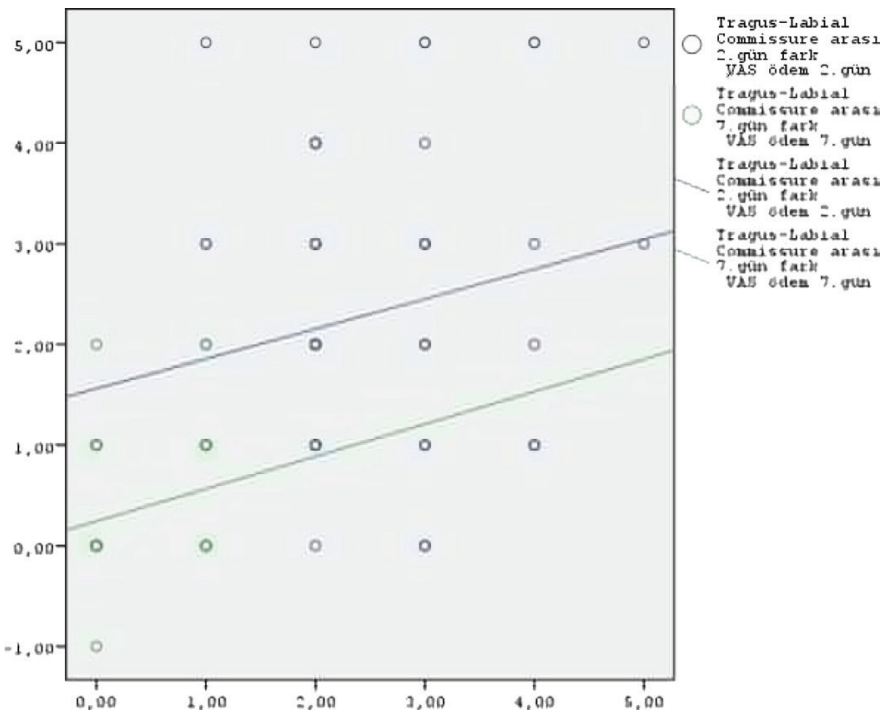

Resim 2. VAS ödem 2. gün ve 7. gün skorları ile aynı günlerdeki mesafe ölçüm lerinde görülen değişim miktarları arasındaki korelasyon.

2.gün VAS ödem skoru ile 2. gün angulus mandibula-lateral canthus arası mesafesinde görülen artış miktarı arasında istatistiksel olarak anlamlı bir ilişki bulunmamaktadır ( $p>0.05)$. 7. gün VAS ödem skoru ile 7. gün angulus mandibula-lateral canthus arası mesafesinde görülen artış miktarı arasında istatistiksel olarak anlamlı bir ilişki bulunmamaktadır ( $p>0.05$ ) (Grafik 3).

2.gün VAS ödem skoru ile preoperatif ölçüme göre 2. gün ağız açıklığında görülen düşüş miktarı arasında pozitif yönlü, \% 30.8 düzeyinde ve istatistiksel olarak anlamlı bir ilişki bulunmaktadır ( $p: 0.017 ; p<0.05)$. 7.gün VAS ödem skoru ile preoperatif ölçüme göre 7. gün ağız açıklığında görülen düşüş miktarı arasında istatistiksel olarak anlamlı bir ilişki bulunmamaktadır ( $p>0.05$ ) (Tablo 3, Grafik 4). 


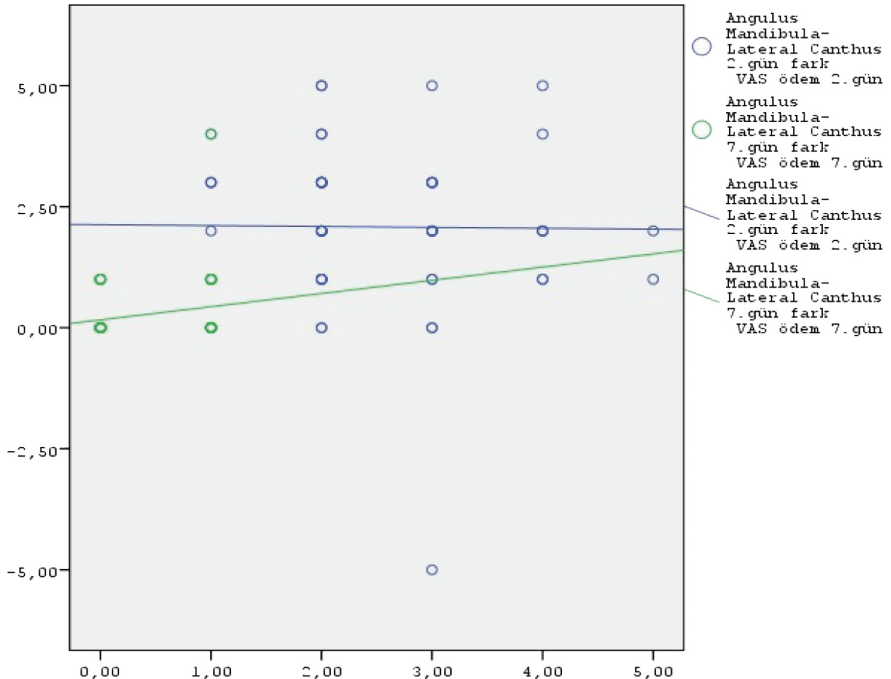

Resim 3. VAS ödem skalası 2. gün ve 7. gün skorları ile aynı günlerdeki ağız açıklığında görülen değişim miktarları arasındaki korelasyon.

Tablo 3. VAS ödem skalası 2. gün ve 7. gün skorları ile aynı günlerdeki ağız açıklığında görülen değișim miktarları arasındaki korelasyon.

\begin{tabular}{|l|l|l|l|l|}
\hline & & & 2.gün & 7.gün \\
\hline \multirow{4}{*}{ Ăğız açıklığı } & 2.gün & $\mathrm{r}$ & 0,308 & \\
\cline { 2 - 5 } & & $\mathrm{p}$ & $0,017^{*}$ & \\
\cline { 2 - 5 } & 7.gün & $\mathrm{r}$ & & 0,175 \\
\cline { 2 - 5 } & & $\mathrm{p}$ & & 0,181 \\
\hline
\end{tabular}

Resim 4. VAS ödem skalası 2. gün ve 7. gün skorları ile aynı günlerdeki ağız açıklığında görülen değişim miktarları arasındaki korelasyon.

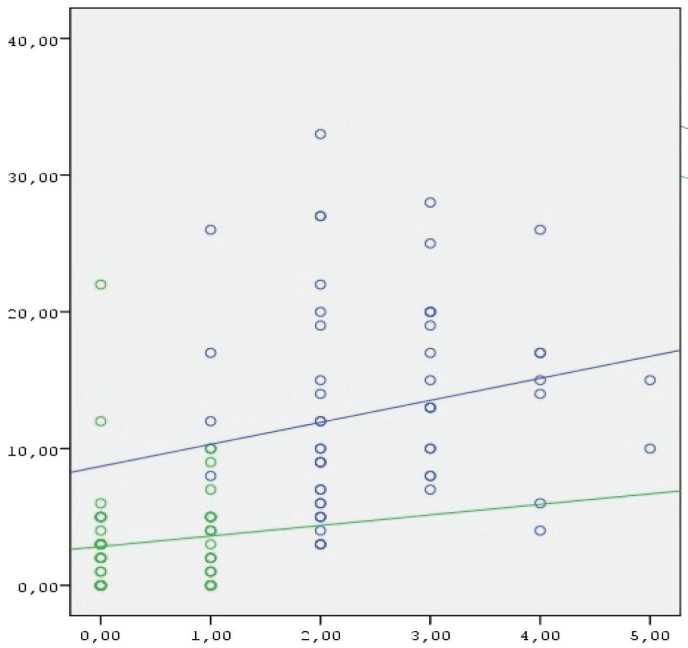

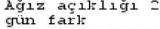
VAS ödem $=$ - gün

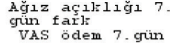

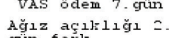

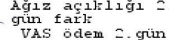

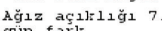

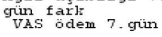

\section{TARTIŞMA}

Cerrahi girişime karşı enflamatuar reaksiyonun bir sonucu olarak ödem oluşur. Ödem bir bakıma yumuşak doku travmasına sekonder olan bir komplikasyondur. ${ }^{11}$ Yetersiz cerrahi teknik, dokulara kötü yaklaşım, flebin aşırı retraksiyonu, dişin pozisyonu ve derinliğine bağlı çekimin zorluğu, çalışma süresinin uzaması, yetersiz irrigasyon gibi etkenler ödemin artmasına neden olan intraoperatif faktörlerdir. ${ }^{12,13}$ Postoperatif 2. günde maksimuma ulaşan ve 7. güne kadar azalarak devam eden ödem gömülü 20 yaş cerrahisinden sonra hastaların en sık yakınmasıdır. Postoperatif dönemde oluşan ödemin takibi için pek çok teknik literatürde açıklanmıştır. ${ }^{7-10}$

Yüzdeki ödemi değerlendirmek amacıyla lateral ve anteroposterior grafilerin ve profil fotoğraflarının değerlendirildiği çalışmalar mevcuttur. Fakat tüm bu yöntemlerin en büyük sorunu üç boyutlu olarak yüzde oluşan değişiklikleri sadece iki boyutlu olarak değerlerlendirebilmesidir. $^{7}$

Bilgisayarlı tomografi ile üç boyutlu olarak daha hassas ölçümler yapılabilmesine rağmen yüksek maliyeti ve hastaların gereksiz radyasyon alması gibi dezavantajları nedeniyle kullanımı terk edilmiştir. Ayrıca bu yöntem ile ödemi tek seferden fazla değerlendirmek mümkün değildir. ${ }^{8}$

Ultrasonografi yöntemi de yirmiyaş cerrahisi sonrası oluşan ödemi değerlendirmek amacıyla kullanılmıştır fakat postoperatif dönemde mekanik irritasyona sebep oalbilen bir yöntem olması bu tekniğin en büyük dezavantajıdır. ${ }^{9}$

Görünür ışık dalga boyu aralığının kullanıldığı üç boyutlu tarayıcılar ile non-invaziv olarak, gerektiği kadar sıklıkta postoperatif ödemi değerlendirmek mümkündür. En sık olarak kullanılan üç boyutlu tarayıcılar lazer tarayıcı, yapılandırılmış ışık tarayıcı ve stereofoto tarayıcıdır. Ancak bu sistemlerin kompleks yapısı verilerin işlenmesinin zaman alması ve sistemin kurulum maliyeti rutin kullanımını kısıtlamaktadır. ${ }^{10}$

Günümüzde gömülü yirmi yaş cerrahisi sonrası ödemin değerlendirilmesinde VAS ödem skalaları da sıklıkla kullanılmaktadır. Bu yöntem hastaların kendilerinin yaptığı subjektif değerlendirmeleri içermesinden dolayı güvenilirliği tartışmaya açık olsa da litaraturde diğer tekniklerle yapılan karşılaştırmalarında yüksek korelasyon oranları gösterilmiştir. ${ }^{3}$

Çalışmamızda; 2. gün VAS ödem skoru ile preoperatif ölçüme göre 2. gün tragus-pogonion arası mesafesinde görülen artış miktarı arasında pozitif yönlü, \% 28.2 düzeyinde ve istatistiksel olarak anlamlı bir ilişki bulunmaktadır (p:0.029; p<0.05).

7.gün VAS ödem skoru ile 7. gün tragus-labial commissure arası mesafesinde görülen artış miktarı arasında pozitif yönlü, \% 28.7 düzeyinde ve istatistiksel olarak anlamlı bir ilişki bulunmaktadır (p:0.026; $p<0.05$ ).

2.gün VAS ödem skoru ile preoperatif ölçüme göre 2. gün ağız açıklığında görülen düşüş miktarı arasında pozitif yönlü, \%30.8 düzeyinde ve istatistiksel olarak anlamlı bir ilişki bulunmaktadır (p:0.017; p<0.05). Diğer ölçümler ile ilgili günlerin VAS Ödem skalası skorları arasında istatistiksel olarak anlamlı bir ilişki bulunmamaktadır.

Bu çalışmada kullanılan, Berge tarafından tarif edildiği haliyle, VAS ödem skalasının hastaya yönelik açıklama- 
larında ödeme ek olarak fonksiyon kaybı ile ilgili ifadelerin de bulunması, hastaların yüksek trismus/ düşük ödem durumunda da VAS ödem skorunu yüksek bir değer olarak işaretlemelerinin, skalanın en önemli dezavantajı olduğunu düşünmekteyiz. Ödemi değerlendirme amacıyla kullanılacak skalaların trismus ile ilgili açıklamalardan arındıııması, trismusun değerlendirilmesi için ayrı bir fonksiyon kaybı skalası kullanılmasının daha güvenilir sonuçlar vereceğine inanmaktayız.

\section{SONUÇLAR}

Çalışmamızda elde ettiğimiz sonuçlar; hastaların subjektif değerlendirmelerine dayanan VAS ödem skalasının, hekim tarafından yüzde yapılan mesafe ölçümleri ile göstermiş olduğu korelasyon bu skalanın postoperatif dönemde ödemi değerlendirmek amacıyla kullanılabileceğini yönündedir. VAS Ödem skalası sayesinde hastanın sadece bilimsel veri toplamak amacıyla kliniğe çağırılması zorunluluğu olmadan kolayca postoperatif 7 günün tamamında veri elde etme imkânı doğmaktadır. Ancak hastanın subjektif değerlendirmesine dayanan VAS ödem skalasının tek basına postoperatif dönemde gözlenen ödemi değerlendirme amacıyla kullanılmasının yeterli olmayacağına, diğer ödem takibi yöntemleri ne ek olarak kullanımının daha güvenilir sonuçlar sunacağına inanmaktayız. Literatürde tarif edilen diğer ödem değerlendirme tekniklerine ek olarak kullanıldığı taktirde; VAS ödem skalasının postoperatif dönemde ödem ve trismus miktarını değerlendirmek amacıyla herhangi bir ek maliyet yaratmadan elde edilen verilere katkı sağlayacağını düşünmekteyiz.

\section{KAYNAKLAR}

1. Peterson LJ, Ellis E, Hupp JR, Tucker MR. Contemporary oral and maxillofacial surgery. St. Louis, Mosby; 1988. 2. Holland CS. The development of a method of assessing swelling following third molar surgery. $\mathrm{Br} \mathrm{J}$ Oral Surg 1979; 17: 104-114.

3. Mantovani E et.al. A split-mouth randomized clinical trial to evaluate the performance of piezosurgery compared with traditional technique in lower wisdom tooth removal. J Oral Maxillofac Surg 2014; 72: 1890-1897.

4. Ozgul O et.al. Efficacy of platelet rich fibrin in the reduction of the pain and swelling after impacted third molar surgery: randomized multicenter split-mouth clinical trial. Head Face Med 2015; 26; 11: 37.

5. Berge TI. The use of a visual analogue scale in observer assessment of postoperative swelling subsequent to third molar surgery. Acta Odontol Scand 1989; 47: 167-174.

6. Chaudhary M, Singh M, Singh S, Singh SP, Kaur G. Primary and secondary closure technique following removal of impacted mandibular third molars: A comparative study. Natl J Maxillofac Surg 2012; 3:10-14.
7. Van Gool AV, Ten Bosch JJ, Boering G. A photographic method of assessing swelling following third molar removal. Int J Oral Surg 1975; 4: 121-129.

8. Cathcart RA. Inflammatory swellings of the head and neck. Surgery (Oxford) 2015; 33: 600-606.

9. Pallagatti S, Sheikh S, Puri N, Mittal A, Singh B. To evaluate the efficacy of ultrasonography compared to clinical diagnosis, radiography and histopathological findings in the diagnosis of maxillofacial swellings. Eur $\mathrm{J}$ Radiol 2012; 81: 1821-1827.

10. Maal TJ et.al. Registration of 3-dimensional facial photographs for clinical use. J Oral Maxillofac Surg 2010; 68: 2391-2401.

11. Fragiskos FD. Oral Surgery. Springer, Berlin, Heidelberg; 2007.

12. Fonseca RJ . Oral and Maxillofacial Surgery. 2nd ed. Elsevier Saunders; 2009.

13. Osborn TP, Frederickson G Jr, Small IA, Torgerson TS. A prospective study of complications related to mandibular third molar surgery. J Oral Maxillofac Surg 1985; 43: 767-769. 
